\title{
Esterleşme Reaksiyonlarında Katalitik Membran Destekli Pervaporasyon Uygulamaları
}

\author{
Derya Ünlü ${ }^{1 *}$
}

Gelis / Received: 27/08/2019

Revize / Revised: 13/05/2020

Kabul / Accepted: 29/06/2020

ÖZ

Kimya endüstrisinin gelişmesi, çeşitli kimyasal ve fiziksel işlemlerde daha fazla çözücü kullanılmasına neden olmuştur. Kullanılan solvent miktarının artması da sektöre olan ekonomik yükü arttırmaktadır. Çözücülerin geri kazanılması, yeniden kullanılması ve saflaştırılması endüstrinin temel gereksinimleri haline gelmiștir. Ayrıca yüksek kaliteli, düşük çevresel etkili, verimi yüksek, ekonomik ürün elde edilmesi önemlidir. Katalitik membran destekli pervaporasyon uygulaması, endüstrilerdeki hem reaksiyon hem de ayırma problemlerine yeni alternatif çözümlerinden biri olarak kabul edilmektedir. Katalitik membran destekli pervaporasyon uygulaması gelişen membran teknolojilerinden biridir. Ayırma ve reaksiyon birimlerini birleștiren hibrit ve entegre bir süreçtir. Bu çalışma, esterleştirme reaksiyonlarının katalitik membran destekli pervaporasyon uygulamaları üzerine yoğunlaşmıştır. İlk olarak, katalitik membran, pervaporasyon ve katalitik membran destekli pervaporasyon hakkında bazı önemli bilgiler verilmiştir. Katalitik membran destekli pervaporasyonun farklı konfigürasyonları tanımlanmış ve açıklanmıştır. Hibrit katalitik membran destekli pervaporasyon işlemlerinin avantajları listelenmiştir. Katalitik membran destekli pervaporasyonu etkileyen faktörler kısaca tartışılmıştır. Literatürdeki önemli katalitik membran destekli pervaporasyon çalışmaları, çalışma koşulları ve elde edilen sonuçlar özetlenmiştir.

Anahtar Kelimeler- Katalitik Membran, Esterleşme, Pervaporasyon, Katalitik Membran Destekli Pervaporasyon Prosesi

1*Sorumlu yazar iletișim: derya.unlu@btu.edu.tr (https://orcid.org/0000-0001-5240-5876)

Kimya Mühendisliği Bölümü, Bursa Teknik Üniversitesi, Mühendislik ve Doğa Bilimleri Fakültesi, Bursa, Türiye 


\title{
Catalytic Membrane Aided Pervaporation Applications in Esterification Reactions
}

\begin{abstract}
The development of the chemical industry has resulted in the usage more solvents in various chemical and physical processes. The increase in the amount of used solvent also increases the economic burden to the industry. The recovery, reuse, and purification of solvents became the essential requirements of the industry. In addition, the obtainment of high-quality, economic product with low environmental impact and high yield is important. The catalytic membrane aided pervaporation application is considered as one of the new alternative solutions of both reaction and separation problems in the industries. Catalytic membrane aided pervaporation application is one of the developing membrane technologies. It is a hybrid and integrated process combining separation and reaction units. This article is concentrated on catalytic membrane aided pervaporation applications of the esterification reactions. Some important information about catalytic membrane, pervaporation and catalytic membrane aided pervaporation has been firstly reported. Different configurations of catalytic membrane aided pervaporation have been defined and explained. Advantages of the hybrid catalytic membrane aided pervaporation processes have been listed. The factors affecting the catalytic membrane aided pervaporation are briefly discussed. The important catalytic membrane aided pervaporation, reaction conditions and the obtained results in literature are also summarized. The important catalytic membrane aided pervaporation studies in literature, operation conditions and the obtained results have been summarized.
\end{abstract}

Keywords- Catalytic Membrane, Esterification, Pervaporation, Catalytic Membrane Aided Pervaporation Process 


\section{INTRODUCTION}

Nowadays, energy-saving and eco-friendly hybrid applications which are combined with chemical reaction and separation process are received a great deal of attention. These hybrid applications are suitable for especially thermodynamic equilibrium limited reactions, such as esterification reaction, etherification reaction [1].

Esters are used in many chemical industries, such as plasticizers, fragrances, perfumes, varnishes, synthetic resins, and adhesives [2]. For this purpose, large quantities of ethyl acetate and butyl acetate are commercially produced. For example, ethyl acetate is one of the most important solvents in the chemical industry. It is used in the production of perfumes, plasticizers, varnishes, synthetic resins, and adhesives. In addition, esters are rather important because many of them have characteristic tastes and odors for using in food and aroma industries [3-4].

Esters are synthesized with the reaction of carboxylic acid with alcohols by the presence of acid catalyst. According to reaction mechanism, firstly, the carbonyl oxygen is protonated by the acid groups of catalysts. This step makes the carbonyl carbon a much better electrophile. This carbonyl carbon interacts with alcohol. The carbonyl carbon bonds with a pair of oxygen and $\pi$ bond breaks. The electrons from $\pi$ bond interact with oxygen, and oxonium ion achieves. This oxonium ion is deprotonated the alcohol and tetrahedral intermediate forms. One of the hydroxyl groups in tetrahedral intermediate takes the proton from protonated alcohol. The elimination of water occurs, and protonated ester achieves. Finally, the ester is deprotonated, and then reaction is completed [5].

Esterification is a commonly used chemical reaction in industry. Esterification reactions are equilibrium reactions. Obtaining high efficiency is possible with the use of excess amounts reactant usage or removing one of the products from the reaction mixture. These techniques change the reaction equilibrium towards the product side. The different separation methods have been combined with the reactor to change the reaction equilibrium. Among these, pervaporation is an alternative separation technology [6-7]. Pervaporation is a membrane based separation process. Application areas are the dehydration of aqueous mixtures, separation of organics from aqueous mixtures, or separation of organic-organic mixtures. Pervaporation is used for the separation of azeotropic mixtures and close boiling-point mixtures. Pervaporation has a great number of advantages according to the conventional separation process "distillation". For instance, azeotropic distillation requires the usage of entrainer for recovery of pure solvents, this means additional cost. Also, high energy consumption and the formation of waste are other disadvantages of azeotropic distillation. Another distillation method is reactive distillation. In order to use the reactive distillation, process needs a great difference in the volatility of product and reactants. Moreover, the combination of reaction and distillation is rather complex in reactive distillation. The most important disadvantage of reactive distillation is high energy consumption and high cost. The most important disadvantage of reactive distillation is high energy consumption and high cost, and high reflux ratio requires If the feed solution or reaction solution forms azeotropic mixture, the reactive distillation process cannot be used [8]. Pervaporation is important alternative process due to the low energy consumption, environmentally friendly technology, no need to additional chemical [9-13]. The low flux value is an important disadvantage of the pervaporation process. In addition weak membrane properties appear as a significant problem in pervaporation. However, these problems can be overcomed with modification of membranes [14-17].

Hybrid processes, combining pervaporation with the reactor, are becoming increasingly common in industry. Both the combination of reaction and separation in a single unit and also increment of conversion make attractive to catalytic membrane aided pervaporation applications. High separation and reaction selectivity, low energy consumption, low operation and investment cost, and compact and modular design are advantages of the catalytic membrane aided pervaporation process [18-19].

In general, polymeric membranes are preferred in catalytic membrane aided pervaporation. Working at low temperature has resulted in energy saving. Dense, homogenous membranes are mostly used for the pervaporation process. Enzymes, homogeneous, and heterogeneous catalysts are added to the polymeric membrane and catalytic membranes are obtained. The usage of enzymatic catalytic membrane eliminates the 
product inhibition for the biochemical reaction. Also, homogeneous and heterogeneous catalysts loaded catalytic membranes can be removed from the reaction mixture easily and reused without any treatment [20].

In catalytic membrane aided pervaporation process, while reaction occurs in the catalytic area of the membrane, the separation is carried out in the separation matrix of membrane. The reaction conversion increases with the removal of one of the products selectively from the reaction medium. The catalytic membrane aided pervaporation process is usually operated with high separation efficiency and high conversion [21-24].

In this paper, applications of catalytic membrane aided pervaporation process for esterification reaction has been reviewed and discussed. Design of system, process parameters and recent applications have been also analyzed.

\section{CATALYTIC MEMBRANE}

The membrane in which reaction and separation occur in a single step is defined as the "catalytic membrane'. The investigation of catalytic membranes is quite new in pervaporation applications. The main advantage of the catalytic membrane application is energy-saving [25].

The combination of selective separation and catalytic functions in a single layer is related to the properties of the used substance. For example, to achieve the high water selectivity, the diffusion of all components outside the water through the membrane should be in low value. To use the catalytic properties effectively, diffusion of the reactants must be high [20].

To obtain the catalytic membrane, the membrane is combined or coated with catalyst or membrane material that demonstrates catalytic feature spontaneous. These are also divided into sub-classes. Catalyst is wrapped on the membrane or the heterogeneous catalyst is embedded in the polymer matrix [26]. When the heterogeneous catalyst is embedded with the polymer matrix, the well-selected polymeric environment makes a positive effect on catalyst performance by controlling the selective sorption of the reactants and products [27].

The used catalysts in catalytic membranes can be homogeneous or heterogeneous catalysts. High reaction yield can be obtained easily by using a homogeneous catalyst in a short time. However, homogeneous catalysts have a number of operational disadvantages. Recovery and reuse is rather difficult. The homogeneous catalysts also cause corrosion problems in reactor. To overcome these problems, homogeneous catalysts are added to the polymeric matrix, and catalytic membranes as heterogeneous catalyst are obtained [28, 29]. Recovery and reuse of heterogeneous catalysts is possible [29-30]. However, heterogeneous catalysts might be leached in the reaction mixture. Leaching decreases the catalytic activity of the catalyst [31]. In addition, to recovery of heterogeneous catalyst from the reaction mixture requires the additional separation process, and to reuse of the catalyst need such as neutralization and washing steps [32].

Figure 1 shows the combination of the selective and catalytic layers. Acid and alcohol diffuse into the catalytic layer and react, convert to ester or water. The resulting ester is diffused back into the feed mixture and the water is separated from the selective layer of the membrane. The thinness of the catalytic layer over the membrane support provides more effective usage [20]. 


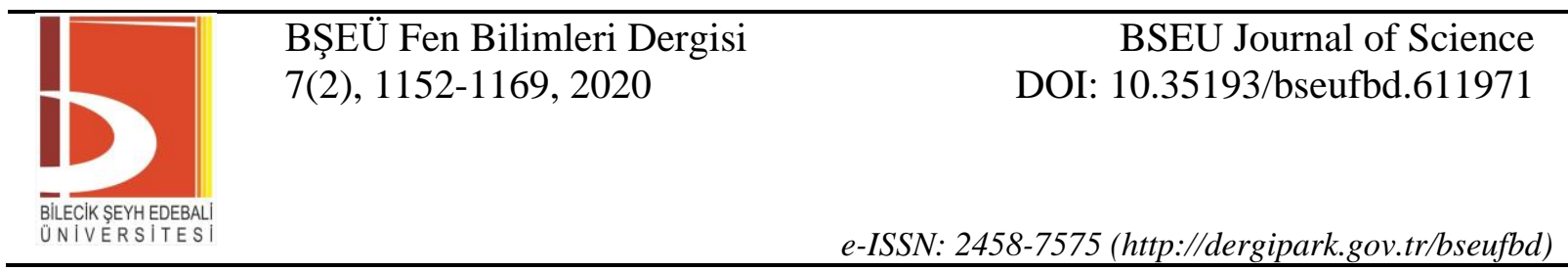
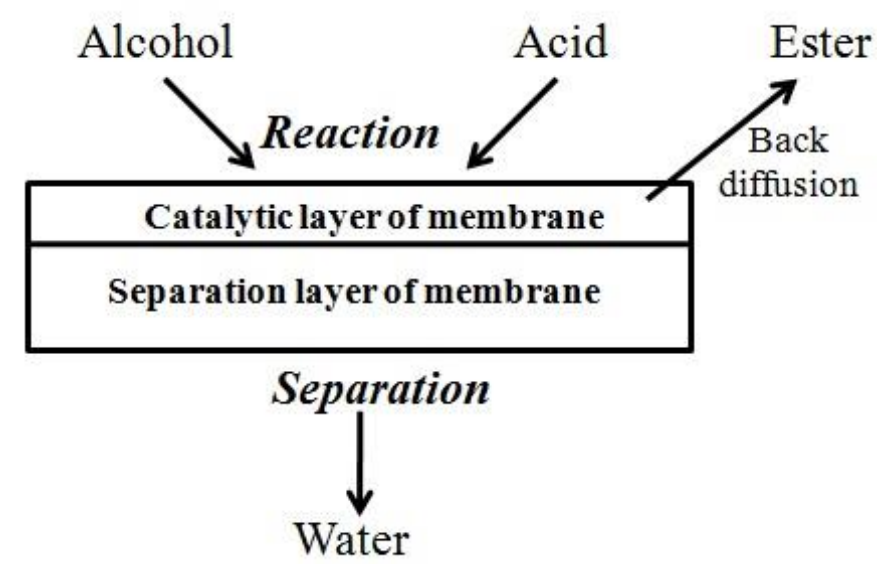

Figure 1. The working principle of the catalytic composite membrane

In catalytic membrane aided pervaporation, there is no mass transfer limitation problem. Choosing a convenient polymeric materials can adjust the diffusion of reactants and products. The determination of optimum polymer concentration is rather important for the catalytic activity. Under this condition, the reactants contact easily with catalysts. High polymer concentration makes the diffusion difficult and prevents the reactants to reaching active sites of the catalyst. The presence of diffusion channels between the polymer molecules in the membrane leads to a high diffusivity of reactants along the membrane by the concentration gradient and reactants reach the active groups of the catalyst without any resistance. Therefore, optimum polymer concentration is an important parameter. The presence of diffusion channels between the polymer molecules in the membrane leads to a high diffusivity of reactants along the membrane by the concentration gradient and reactants reach the active groups of the catalyst without any resistance. The reaction materializes in the reaction mixture-membrane interface, high conversions achieves with the catalytic membrane [33].

Catalytic membrane aided pervaporation involves not only mass transport along the membrane but also heat transfer. Pervaporation process involves a phase change from a liquid solution to a vapor solution. This change is required the vaporization enthalpy of liquid feed stream. Consequently, the feed temperature decreases. The permeate stream is vaporized on the permeate side of the membrane. The heat of feed side is used. Due to the reducing of temperature, the partial pressure of the components and the driving force for mass diffusion decrease. Re-heating is required. Therefore, the controlled and continuous heating is required in the catalytic membrane aided pervaporation [8].

The usage of the catalytic membrane provides the opportunity to reuse of catalyst and no need neutralization of catalyst. The catalytic membrane can be omitted from the reaction medium easily and reused without any treatment [34].

\section{PERVAPORATION}

Pervaporation is used in the dehydration of organic solvents, in the removal of volatile organic compounds from aqueous solutions, in the separation of organic-organic mixtures. There is a great number of studies in literature for the first two applications. Pervaporation is rather successful in these applications.

The chemical structure of the membrane is not damaged from the feed mixture. The membrane should be demonstrated selectivity to only one component in the feed mixture. At this point, the selection of membrane for the separation of organic-organic mixtures is quite difficult. In typical pervaporation processes, while the flux value of the membrane is obtained as high, the selectivity values are usually low. Pervaporation also has advantages when it is used as a hybrid with other processes [35]. The example of a hybrid process is shown schematically in Figure 2. 


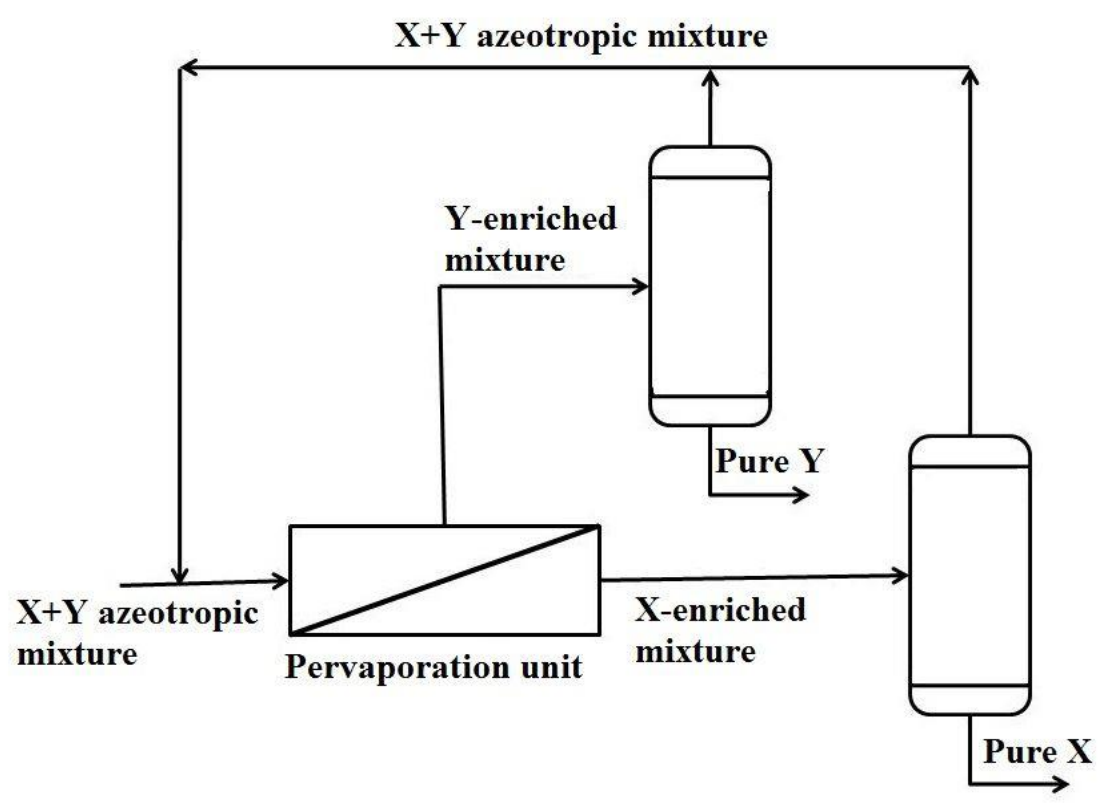

Figure 2. Scheme of pervaporation-distillation for the azeotropic separation

In the single-step pervaporation of the azeotropic mixture of $\mathrm{A}-\mathrm{B}$, the membrane has a high affinity to component A, so the permeate side contains component A. B remains in the retentate side. To acquire the component of B as pure, B should be fed to the distillation unit. In the pervaporation process, liquid mixture contacts with the top side of the membrane, the vacuum is applied on the downside, diffusion occurs, and permeate stream obtains. Pervaporation by vacuum pump is shown in Figure 3 (a). The alternative to vacuum, carrier gas can be used for the creation of pressure difference. This type of pervaporation can be seen in Figure 3 (b). In pervaporation, the permeate stream is collected as the vapor phase in the cold trap; it condensed and obtained in liquid form.

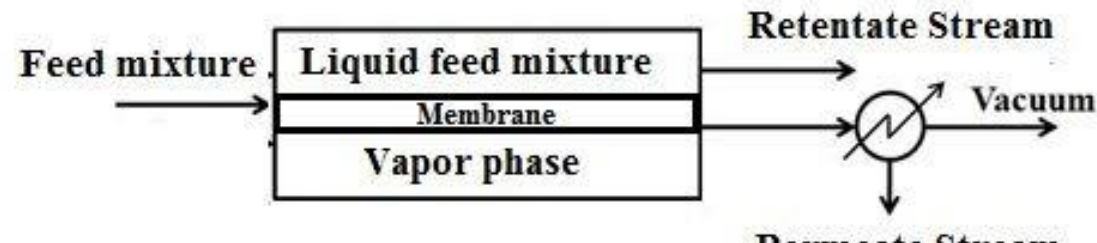

(a)

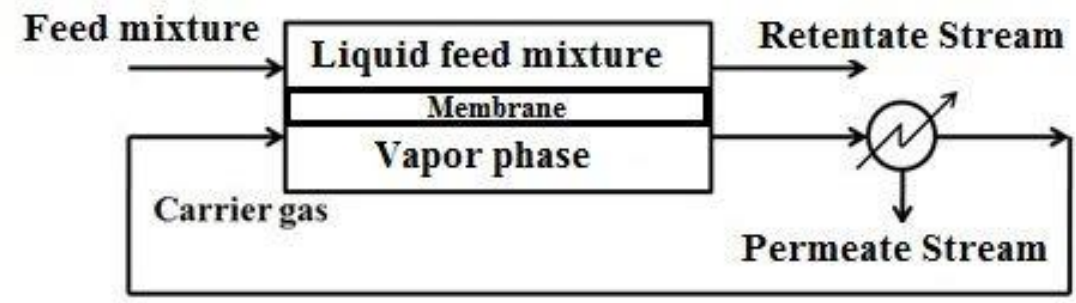

(b)

Figure 3. Scheme of pervaporation (a) by using vacuum (b) by using carrier gas 


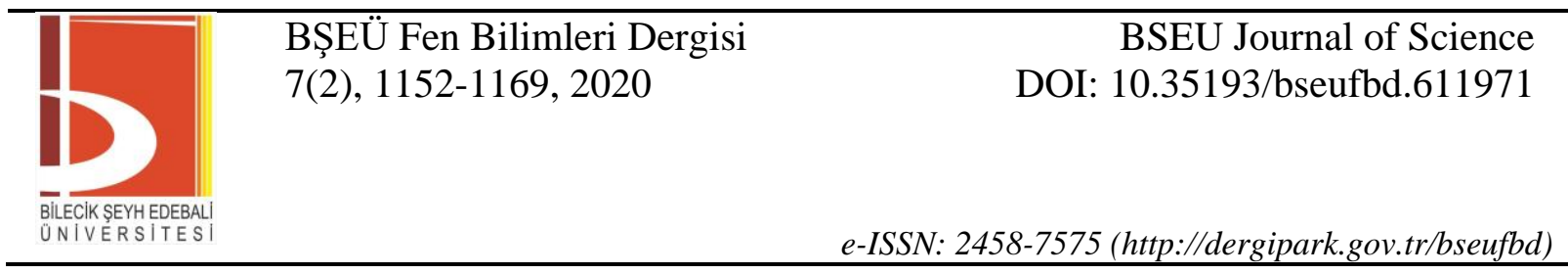

The purification behavior of pervaporation is characterized by flux and selectivity.

Selectivity is described as shown in Equation 1.1;

$$
\alpha_{\mathrm{ab}}=\frac{\mathrm{C}_{\mathrm{a}_{\mathrm{p}}} / \mathrm{C}_{\mathrm{b}_{\mathrm{p}}}}{\mathrm{C}_{\mathrm{a}_{\mathrm{f}}} / \mathrm{C}_{\mathrm{b}_{\mathrm{f}}}}
$$

$\mathrm{C}_{\mathrm{a}}$ and $\mathrm{C}_{\mathrm{b}}$ are the concentrations of $\mathrm{a}$ and $\mathrm{b}$ components. $\mathrm{p}$ and $\mathrm{f}$ define the permeate and the feed, respectively. The separation factor depends on the solubility and diffusivity of the components in the membrane, and the interaction between the membrane and the feed solution [36].

There are two types of selectivity as solubility selectivity and diffusion selectivity. Solubility selectivity is rather important for the separation. One of the components in the feed shows high solubility value in the membrane. This component significantly affects the swelling degree of the membrane. Higher swelling may cause to decreasing in selectivity and decreasing of mechanical strength of membranes. The blending of polymers, cross-linking, concentrated emulsion polymerization, copolymerization, etc. are used for the preparation of membranes with the desired properties [35].

Flux is described as the weight of substance through the membrane at a unit of time, per unit active area of the membrane. Flux depends on the thickness and permeability of the membrane [37]. The flux is shown in Equation (1.2);

$$
\mathbf{J}_{\mathrm{i}}=-\mathrm{D}_{\mathrm{i}} \frac{\mathrm{dC_{i }}}{\mathrm{dx}}
$$
gradient [38].

$\mathrm{J}_{\mathrm{i}}$; flux of $\mathrm{i}$ component $\left(\mathrm{g} / \mathrm{cm}^{2} . \mathrm{h}\right), \mathrm{D}_{\mathrm{i}}$; diffusion coefficient of $\mathrm{i}$ component $\left(\mathrm{cm}^{2} / \mathrm{h}\right), \mathrm{dC}_{\mathrm{i}} / \mathrm{dx}$; concentration

The driving force in pervaporation is chemical potential gradient. Transport through the membrane is defined with the "solution-diffusion mechanism". This transport mechanism is shown in Figure 4. In this mechanism, the membrane has a high affinity to one of the components in the feed solution and this component is absorbed perfectly and dissolves in the dense membrane. The component transports along the membrane by the diffusion process and desorbs from the downside of the membrane [39].

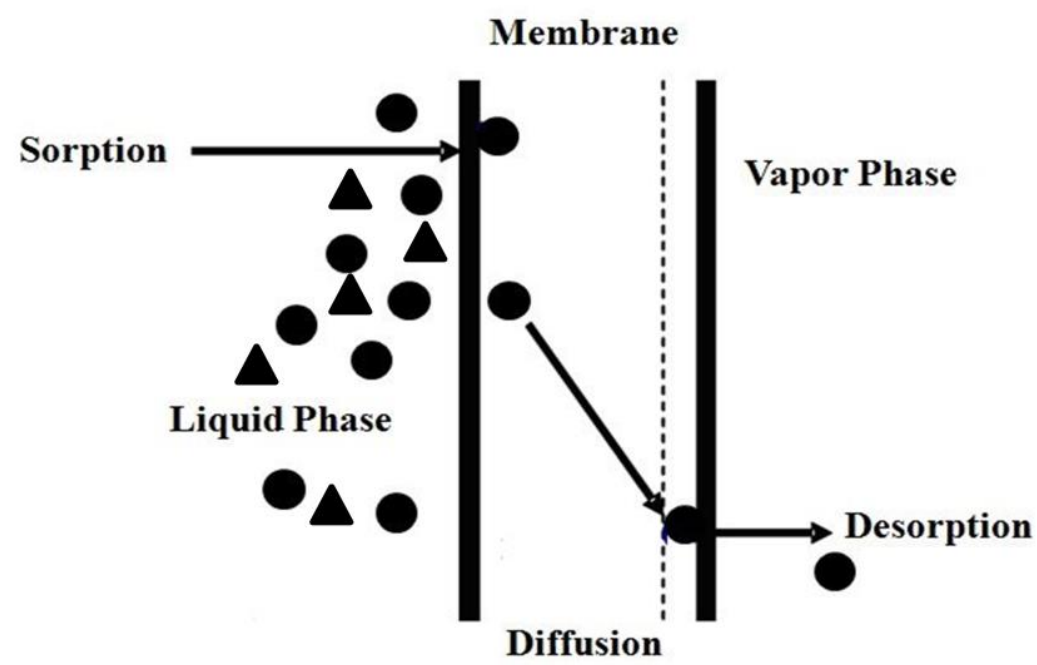

Figure 4. Solution-diffusion mechanism 


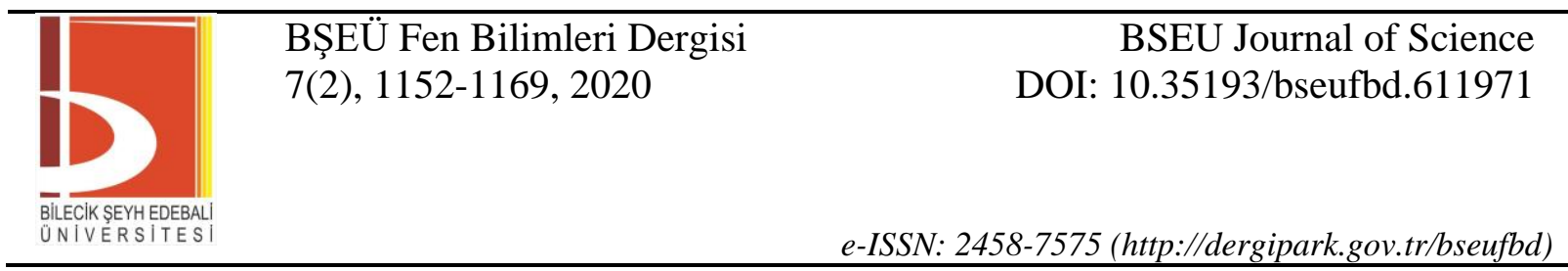

Mechanism of solution-diffusion consists of three steps:

1) Sorption: The components at the membrane/feed solution interface are absorbed into the membrane by selective sorption behavior.

2) Diffusion: The absorbed components are diffused through the membrane under the chemical potential gradient. 40].

3) Desorption: The components passing through the membrane are separated in the vapor phase [30,

The separation success of the membrane is related to the solubility of components on the membrane and diffusivity of the components through the membrane. Transport is provided with differences in pressure. The feed mixture is usually under atmospheric pressure. Therefore, the driving force for transport through the membranes is obtained by reducing the partial vapor pressure on the downstream [39].

\section{CATALYTIC MEMBRANE AIDED PERVAPORATION (PERVAPORATION MEMBRANE REACTOR)}

The aim of the combination of chemical reactor and membrane unit is to realize the reaction and separation in one unit. Nowadays the membrane is not used only as a separator, but also as a catalyst. Reaction and separation are realized simultaneously in the pervaporation process by using catalytic membranes. This process is catalytic membrane aided pervaporation. This process is known as the pervaporation catalytic membrane reactor (PVCMR) in literature [41]. Figure 5 shows the schematic of the catalytic membrane aided pervaporation [42].

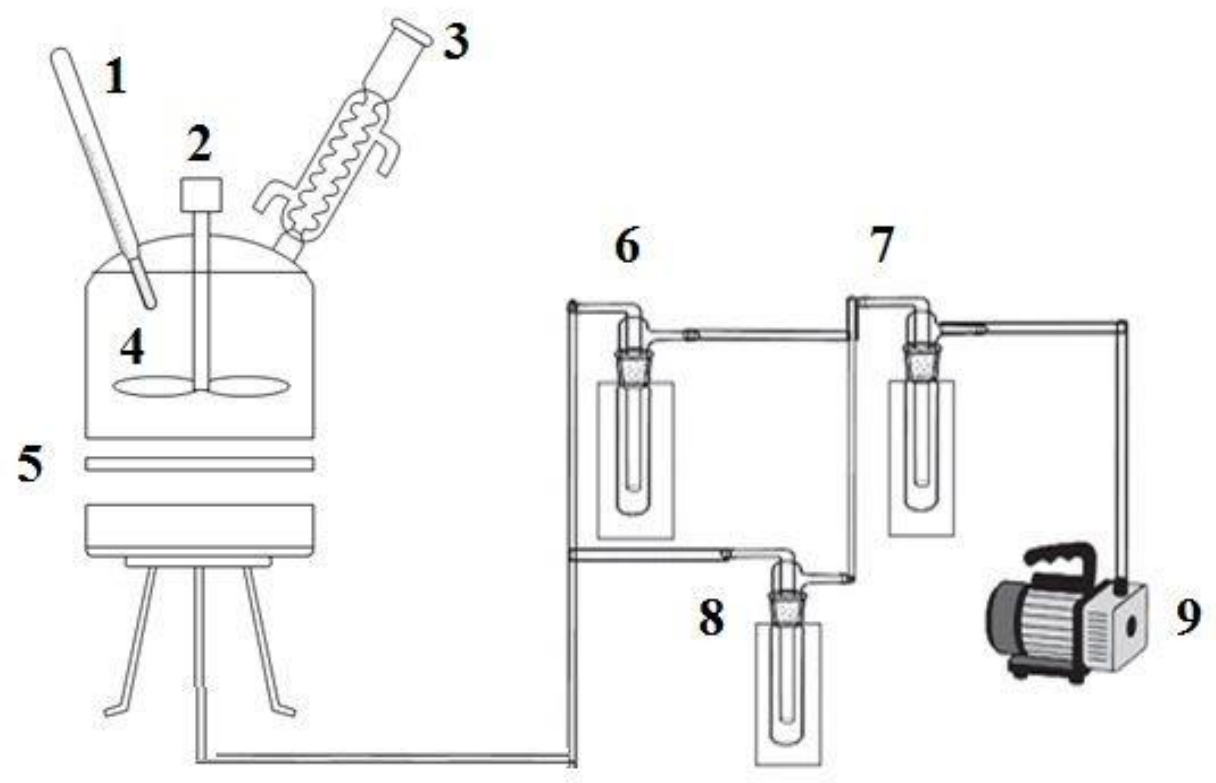

Figure 5. Catalytic Membrane Aided Pervaporation: (1) temperature measurement device; (2) mechanical mixer; (3) condenser; (4) reaction vessel; (5) membrane; (6, 7 and 8) Cold traps; (9) vacuum pump.

\section{A. The Advantages Of Catalytic Membrane Aided Pervaporation}

In recent years, catalytic membrane aided pervaporation is utilized as the innovative, energy-saving and environmentally friendly separation technology. The aim of the usage of the pervaporation process is the 
removal of one of the products in the reaction mixture and change the reaction equilibrium. Thus, the full conversion of reactants is acquired.

The catalytic membrane aided pervaporation process has some advantages according to the conventional batch reactor. These advantages have been listed below.

1) The membrane acts as an active role in reactive processes.

2) The catalytic membrane aided pervaporation creates closer contact between reactants and catalyst.

3) When a homogeneous or heterogeneous catalyst is embedded in the membrane, the recovery, regeneration and reuse of the catalyst are possible.

4) Reaction and separation are carried out simultaneously and conversion is increased.

5) While the reactants remain in the reactor, the products are removed.

6) Pervaporation is a rate controlled process; separation is not limited by volatility such as distillation.

7) Pervaporation process can be carried out by an appropriate membrane at the low reaction temperature for the reaction, which is a good alternative for temperature sensitive catalysts and products.

8) Undesired byproducts and reactions are prevented.

9) Recycling of intermediate products is possible, otherwise undesirable reactions may occur if the reactants remain in the reactor

10) High conversion is obtained at stoichiometric feed flow rates.

11) Reaction heat can be used in separation.

12) Low capital investment.

13) Low reaction time.

14) Mild operation conditions.

The catalytic membrane aided pervaporation has been a substantial alternative process to conventional process due to these advantages [44-47].

\section{B. Factors Affecting Catalytic Membrane Aided Pervaporation Process}

The effect of the four different operation conditions on the conversion and separation was investigated in three groups:

- Factors affecting the direct esterification reaction (catalyst concentrations and molar feed ratios)

- Factors directly affecting pervaporation kinetics (ratio of membrane area to reaction volume) (temperature)

- Factors affecting the esterification reaction and the pervaporation kinetics at the same time

Temperature is the most important parameter for affecting system performance. The reaction rate increases with temperature due to the Arrhenius law, and pervaporation also accelerates with temperature. The vapor pressures of components are increased with temperature in pervaporation.. This creates the driving force and facilitates diffusion. 


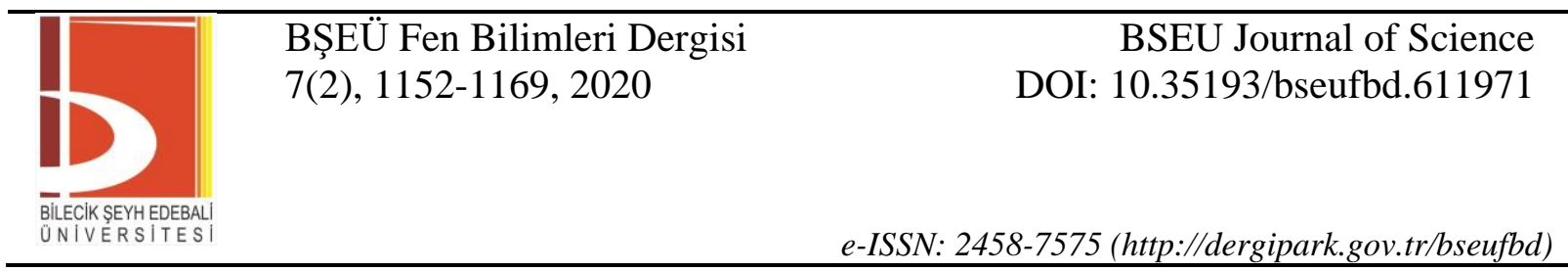

The second important parameter is the molar feed ratio. The usage of a high molar feed ratio requires additional separation step for the recycles of the non-reacting components.

The third factor is the ratio of membrane area to reaction volume. This is an important factor for pervaporation. The ratio of membrane area to reaction volume can be changed by using membranes with different areas or using the different reaction volumes.

Catalyst concentration has a weak effect on the catalytic membrane aided pervaporation system [48].

\section{Configurations of Catalytic Membrane Aided Pervaporation Process}

There is different type of catalytic membrane aided pervaporation configurations. Batch, recycle batch, and recycle continuous and continuous catalytic membrane aided pervaporation processes are shown in Fig. 6.
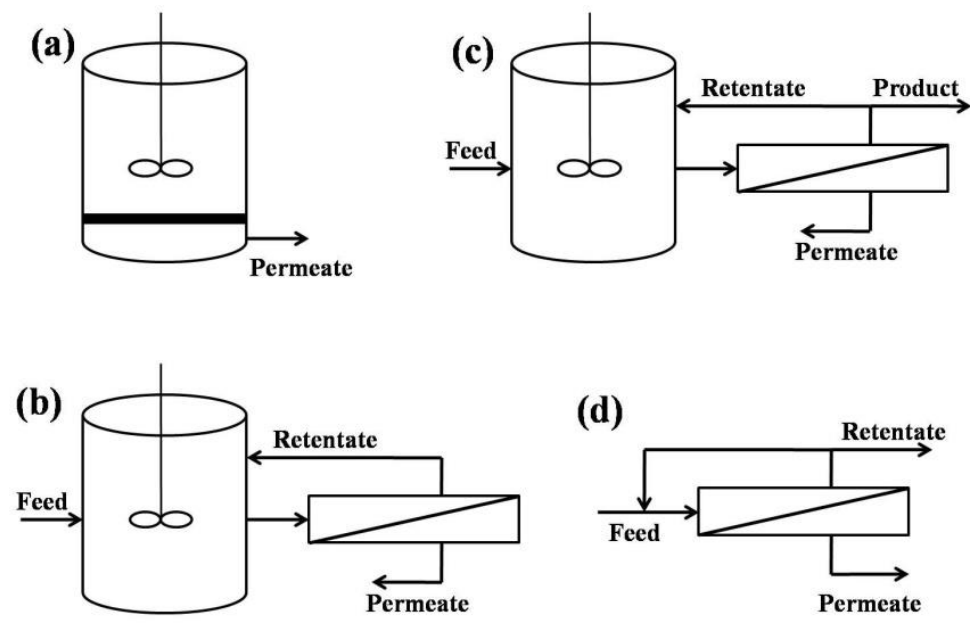

Figure 6. Pervaporation aided esterification reaction flow diagrams (a) batch (b) recycle batch (c) recycle continuous (d) continuous.

Batch and recycle batch configurations in Figure 6 a, b are usually preferred in the catalytic membrane aided pervaporation process. The membrane is placed in the batch reactor configuration. Reactor and separation are two different units in the recycling batch configuration. In this process, the liquid reaction mixture is dehydrated in the membrane unit and the other components return to the reactor. This process has an advantage: the membrane area is separated from the reactor volume. The cleaning of membrane is easy in this configuration. Two membrane modules can be used. The other one can be cleaned while one of them is in operation. In case of failure of the second membrane module, the process can be carried out with the other membrane module.

Recycle continuous configuration is shown in Figure 6 (c). When compared with the recirculating batch catalytic membrane aided pervaporation process (Figure 6 (b)), feed and product stream are separate in the configuration and the product is manufactured continuously. The continuous process is used in a large volume reactor. As shown in Figure 6 (d), membrane and reactor are combined in a single unit for the tubular flow continuous configuration. The advantages of the combination of membrane and reactor in a single unit are efficient production and separation, modular design, decrement of energy, operation, and investment costs [20].

\section{Applications of Catalytic Membrane Aided Pervaporation Process}

Sun et al. (2020) synthesized the polyvinyl alcohol/ $\mathrm{SO}_{4}{ }^{2-}$-anodic aluminium oxide ( $\mathrm{PVA} / \mathrm{SO}_{4}{ }^{2-}-\mathrm{AAO}$ ) membranes. $\mathrm{SO}_{4}{ }^{2-}$-AAO was used as the catalyst. The catalytic activity of membrane was examined in the esterification between ethanol and acetic acid. Acid conversion value reached above $96 \%$ after the 16-hours' 
reaction in the pervaporation aided esterification. The synthesized membrane had excellent stability. After 5 reuse, acid conversion value remained above $90 \%$ [49].

Li et al. (2020) conducted the esterification reaction of oleic with methanol in the pervaporation catalytic membrane reactor. Poly (vinyl alcohol) (PVA) hybrid catalytic membranes were prepared for this reaction. The PAL-PIL was chosen as a solid catalyst. The highest separation performance was obtained as separation factor of 111 and total flux of $397 \mathrm{~g} \cdot \mathrm{m}^{-2} \cdot \mathrm{h}^{-1}$ for $80 \mathrm{wt} \%$ ethanol aqueous at $70^{\circ} \mathrm{C}$ [50].

Cao et al. (2020) produced the yeast-immobilized catalytic membrane by using phase inversion method. The separation layer of membrane was prepared by using polydimethylsiloxane (PDMS) and the catalytic layer was fabricated by coating a porous yeast/polyether sulfone on separation layer. An increase of 35\% was observed in ethanol productivity. The catalytic membrane showed a stable structure in four cycles of pervaporation membrane reactor experiments [51].

Li et al. (2019) prepared the catalytic composite membrane. Catalytic layer of membrane was comprised of homogeneous catalyst "poly (styrene sulfonic acid)" and polyvinyl alcohol. The separation layer of membrane was blended of sodium alginate and polyvinyl alcohol. The prepared catalytic membrane was used to synthesis of ethyl propionate. While the reaction conversion was obtained as $91.6 \%$, flux and separation factor were obtained as $260 \mathrm{~g} \mathrm{~m}^{-2} \mathrm{~h}^{-1}$ and 91 [52].

Zhang et al. (2019) synthesized the ionic liquids-functionalized PVA catalytic membrane. Pervaporation enhanced the conversion as a ratio of $19 \%$ [53].

Unlu and Hilmioglu (2019) prepared the phosphomolybdic-acid-loaded PVA membrane for the esterification reaction of glycerol with acetic acid. The reaction was attempted under mild operation conditions according to literature $\left(75^{\circ} \mathrm{C}\right.$, catalyst concentration $5 \mathrm{wt} \%$, and molar feed ratio $\left.6: 1\right)$. Under these reaction conditions, while the glycerol conversion was obtained as $100 \%$, the selectivity of triacetin was obtained as $76 \%$ [54].

Unlu and Hilmioglu (2018) studied the reaction of levulinic acid with ethanol by using the sulfosuccinic acid loaded chitosan membrane. The sulfosuccinic acid is a homogeneous liquid catalyst. $93.33 \%$ of levulinic acid conversion was achieved in the catalytic membrane aided pervaporation process [55].

The catalytic membrane aided pervaporation process has been also studied by Unlu et al. (2017) for fuel bioadditive ethyl levulinate production. The authors prepared the sulfated zirconia catalyst and used it to synthesize of the catalytic membrane. The hydroxyethyl cellulose was chosen as a polymeric matrix. The hydroxyethyl cellulose membrane showed high good separation behavior. Conversion of catalytic membrane aided pervaporation process was $95 \%$ compared to $34.92 \%$ without pervaporation [56].

Nigiz and Hilmioglu (2017) prepared catalytic membrane by the use of boric acid as catalyst and the use of carboxymethyl cellulose as polymeric matrix and were utilized in a catalytic membrane aided pervaporation process system to synthesize ethyl lactate. While the maximum conversion was obtained as $54 \%$ in the batch reactor with initial feed molar ratio of 3,83\% lactic acid conversion was achieved at the same feed molar ratio in the PVCMR [57].

Rhizomucor miehei lipase-coated alginate biocatalytic membrane has been suggested by Nigiz and Hilmioglu (2017) for the production of ethyl lactate. The effects of reaction parameters, such as the amount of lipase, reaction temperature and initial molar ratio, on lactic acid conversion were investigated to evaluate the performance of the system. The highest lactic acid conversion was obtained as $63 \%$ in the pervaporation biocatalytic membrane reactor at $50{ }^{\circ} \mathrm{C}$, while the lactic acid conversion was $37 \%$ in the batch reactor under the same reaction conditions. The obtained results were shown that the pervaporation biocatalytic membrane reactor is a good alternative for the ethyl lactate reaction [58].

Qing et al. (2017) carried out the catalytic membrane aided pervaporation process using $\mathrm{Zr}\left(\mathrm{SO}_{4}\right)_{2} \cdot 4 \mathrm{H}_{2} \mathrm{O}$ loaded PVA membrane. A $43 \%$ conversion increment was realized according to the equilibrium conversion. Esterification of acetic acid with n-butanol was chosen as a model reaction [59]. 
Unlu and Hilmioglu (2016) studied in the catalytic membrane aided pervaporation process with $\mathrm{Zr}\left(\mathrm{SO}_{4}\right)_{2} \cdot 4 \mathrm{H}_{2} \mathrm{O}$ coated chitosan pervaporation membranes for the production of ethyl acetate. The composite catalytic membrane was prepared by the coating and solution casting method. $\mathrm{Zr}\left(\mathrm{SO}_{4}\right)_{2} \cdot 4 \mathrm{H}_{2} \mathrm{O}$ was used as a heterogeneous catalyst in the catalytic layer of the membrane. The catalytic layer was coated on the selective layer. Esterification is a typical equilibrium reaction controlled by thermodynamic. The reaction was carried out in the batch reactor, and catalytically active membrane reactor and performances of reactors were compared. The effect of reaction parameters, such as temperature, catalyst loading and initial mole ratio on the acetic acid conversion was investigated. The acetic acid conversion reached to $85 \%$ under the optimum reaction conditions. Conversion value increased by approximately 55\% compared to the equilibrium conversion value at the same reaction conditions [42].

A novel composite structure was utilized by Zhang et al. (2014) for the production of n-butyl acetate. The catalytically active pervaporation membrane had three layers. The top layer of the membrane was a porous catalytic layer, the middle layer is the dense PVA selective layer and the bottom layer is the commercially available PES support layer. Styrene-divinyl benzene copolymer beads were used as a catalyst in the catalytic layer of the membrane. Acetic acid conversion reached $91.4 \%$ in $20 \mathrm{~h}$ at $85^{\circ} \mathrm{C}$, while the equilibrium conversion was only $71.9 \%$ in the same reaction conditions. The catalytic membrane represented good performance in consecutive pervaporation experiments, and it can confirm by SEM images [60].

Zhang et al. (2014) studied in lauryl stearate production by lipase-catalyzed esterification, using a bio catalytic membrane. Candida rugosa lipase was immobilized polyvinyl alcohol (PVA) membrane. Polyvinyl alcohol (PVA)/polyether sulfone (PES) bilayer was prepared. The composite membrane was characterized by SEM analyses and the "sandwich-like" membrane structure was observed in the SEM images. PVA/PES composite membrane showed better thermal and $\mathrm{pH}$ stability according to free lipase. The membrane had the recycle and reuse features. The conversion enhancement of approximately $40 \%$ was observed in a pervaporation membrane reactor compared to the batch reactor. Removal of by product water by pervaporation process would help improve the lipase activity. Pervaporation process also shifted the equilibrium of the reaction to the product direction, thus acid conversion was increased [61].

Liu and Chen (2002) presented a model for the production of n-butyl acetate by $\mathrm{Zr}\left(\mathrm{SO}_{4}\right)_{2} \cdot 4 \mathrm{H}_{2} \mathrm{O}$ catalyst loaded membrane in catalytic membrane aided pervaporation process. The effect of temperature, the initial mole ratio of acetic acid over n-butanol, the ratio of the effective membrane area over the volume of reacting mixture and catalyst content, on the esterification yield was investigated. Similar numerical and experimental results were obtained in the model equations [62].

The PVA pervaporation catalytic membrane was prepared on porous ceramic plate support by Zhu and Chen (1998) to study the acetic acid/ethanol esterification reaction. SEM (scanning electron microscopy), IR (infra-red) (ATR) (attenuated total refraction) and XPS (X-ray photoelectron spectrometry) were used to characterize the catalytic membrane structure. The reaction was carried out in a catalytic membrane aided pervaporation process. The conversion of n-butyl alcohol was obtained as $95 \%$ by using PVA catalytic membrane. Different reaction parameters, temperatures, catalyst concentrations, and initial reactant molar ratios were studied experimentally [63].

$\mathrm{TiO}_{2}$-SPPESK-PES nanocomposite membranes have been used by Ma et al. (2013) in the esterification reaction of acetic acid with ethanol. The pore structure and morphology, water uptake, hydrophilic nature, degree of geometric swelling, mechanical properties and catalytic properties of the nanocomposite membranes were investigated. The kinetic model was described for the reaction. $\mathrm{TiO}_{2}$-SPPESK-PES nanocomposite membranes show good stability and mechanical properties [64].

Amberlyst 15 catalysts loaded composite ceramic/poly (vinyl) alcohol membranes were prepared by Peters at al. (2007) for the production of butyl acetate. The catalytic membrane was prepared by using dip-coat technique. The catalytic membrane is responsible for the catalytic activity and water removal [65]. 
Peters et al. (2005) also prepared the zeolite-coated membrane layers by dip-coating technique. TEOS and Ludox AS-40 were used as binder material for the deposition of zeolite H-USY on silica membranes. Membrane pre-treatment and the addition of the binder were found as important parameters [66].

Liu et al. (1999) studied in a pervaporation assisted catalytic membrane reactor for the manufacturing of n-butyl acetate by $\mathrm{H}_{3} \mathrm{PW}_{12} \mathrm{O}_{40}$ /Polyvinyl alcohol (PVA) catalytic membranes on porous ceramic plates. SEM (scanning electron microscopy) and XPS (X-ray photoelectron spectrometry) were used to characterize the membrane structure. The membrane structure does not change after the $24 \mathrm{~h}$ reaction time [67].

Figueiredo et al. (2008) synthesized the catalytic composite membrane. While the separation layer of the membrane was the Pervap 1000, the catalytic layer of membrane was catalyst loaded PVA membrane. Synthesis of ethyl acetate was chosen as a model reaction. Amberlyst 15 and Amberlyst 35 were used as the catalyst. A catalytic membrane was synthesized by coating the Pervap membrane with a thin layer. The catalytic layer included catalyst particles in poly (vinyl alcohol) solution. 60\% conversion enhancement was determined in the catalytic membrane reactor [68].

Composite catalytic membrane "zeolite coated ceramic membrane" was used by Peters et al. (2005) for the synthesis of butyl acetate. Conversion of acid was obtained as $85 \%$ in a catalytic membrane aided pervaporation process [24].

Bagnell et al. (1993) was used Nafion membranes for the synthesis of esters with different alcohols. Nafion membrane has catalytic properties. The yields of esters as methyl acetate and n-butyl acetate were determined as $77 \%$ and $95 \%$, respectively [69].

David et al. (1992) were prepared the blend membranes by using the poly (acrylonitrile) (PAN)-poly (styrene sulfonic acid) (PSSA) and the poly (vinyl alcohol) (PVA)-PSSA. The reaction was carried out for $12 \mathrm{~h}$. Conversion was obtained as $80 \%$ at the end of the $12 \mathrm{~h} \mathrm{[70].}$

All studies in literature show that catalytic membrane aided pervaporation give high reaction and separation yield according to the conventional process. In addition, this technology has some important advantages such as economical, low energy consumption, environmental friendly, easy installation, scale up, etc. Catalytic membrane aided pervaporation is considered that it will be one of the significant technology in the future. In recent years, it is not used only in laboratory scale but also used in industrial scale. The integration of the reaction and separation in a single step is an important alternative to the batch processes for industry. Catalytic membrane aided pervaporation is promising technology for both nowadays and future. Obtaining a product of high quality and purity in a single unit is possible with catalytic membrane aided pervaporation.

\section{CONCLUSION}

The catalytic membrane aided pervaporation processes receive a great deal of attention in recent years. The catalytic membrane aided pervaporation process is considered as an alternative to the reactive distillation process. In this paper, it has been shown the various catalytic membrane aided pervaporation configurations. The configurations have been classified as batch, continuous and recycle. The design types are explained and the advantages of different configurations are listed and compared to each of them.

The main advantage of catalytic membrane aided pervaporation is energy-saving. Additional separation step is not required. Also, the usage of catalytic membrane is a good alternative to other homogeneous and heterogeneous catalysts. Because, homogeneous and heterogeneous catalysts have some problems such as corrosion for the reactor and separation from the reaction mixture. However, the catalytic membranes can be used repeatedly and recovery and reuse are easy.

The chosen of membrane material is rather important for the performance of catalytic membrane aided pervaporation. Membrane material takes a role in the sorption and diffusion of reactants and products. In this paper, a search of the application of catalytic membrane for the esterification reaction in the literature was given. Studies in the catalytic membrane aided pervaporation process are limited in the literature. The catalytic membrane studies by using pervaporation are summarized in the paper. 
In most cases, hydrophilic membranes have been chosen as the polymeric material in the catalytic membrane aided pervaporation applications because water is a by-product and undesired product for the esterification reactions. Hydrophilic membranes also prevent the diffusion of the organic components from the membrane and keep the catalysts in the membrane. High conversion and high selectivity values are acquired in the catalytic membrane aided pervaporation processes due to the removal of water.

In brief, catalytic membrane aided pervaporation is an innovative reaction aided separation technology. It is an economic, safe and eco-friendly process. In the future, it is believed that catalytic membrane aided pervaporation will find application in the industry if suitable, mechanical and chemical stable and long lived of membrane is developed.

\section{REFERENCES}

[1] Rathod, A. P., Wasewar, K. L., \& Sonawane, S. S. (2013). Enhancement of esterification reaction by pervaporation reactor: an intensifying approach. Procedia Engineering, 51, 330-334.

[2] Yanti, H., Wikandari, R., Millati, R., Niklasson, C., \& Taherzadeh, M. J. (2014). Effect of ester compounds on biogas production: beneficial or detrimental?. Energy Science \& Engineering, 2(1), 22-30.

[3] Yuan, H.-K., Ren, J., Ma, X.-H., \& Xu, Z.-L. (2011). Dehydration of ethyl acetate aqueous solution by pervaporation using PVA/PAN hollow fiber composite membrane. Desalination, 280(1-3), 252-258.

[4] Zhang, X. H., Liu, Q. L., Xiong, Y., Zhu, A. M., Chen, Y., \& Zhang, Q. G. (2009). Pervaporation dehydration of ethyl acetate/ethanol/water azeotrope using chitosan/poly (vinyl pyrrolidone) blend membranes. Journal of Membrane Science, 327(1-2), 274-280.

[5] Brown, W., Foote, C., Iverson, B., \& Anslyn, E. (2011). Organic Chemistry, 5th Edition, Brooks/Cole Cengage Learning, USA.

[6] Wasewar, K., Patidar, S., \& Agarwal, V. K. (2009). Esterification of lactic acid with ethanol in a pervaporation reactor: modeling and performance study. Desalination, 243(1-3), 305-313.

[7] Das, S., Banthia, A.K., \& Adhikari B. (2007). Improved conversion to ethyl acetate through removal of water of esterification by membrane pervaporation. Indian Journal of Chemical Technology, 14, 552-559.

[8] Cannilla, C., Bonura, G., \& Frusteri, F. (2017). Potential of Pervaporation and Vapor Separation with Water Selective Membranes for an Optimized Production of Biofuels-A Review. Catalysts, 7, 187.

[9] Marszałek, J., Rdzanek, P., \& Kamiński, W. (2014). Improving performance of pervaporation membranes for biobutanol separation. Desalination and Water Treatment, 56(13), 3535-3543.

[10] Wang, Q.W., Shi, B.L., \& Ji, L.Y., (2014). Pervaporation separation of ethanol via adsorbent-filled silicon rubber membranes. Membrane Water Treatment International Journal, 5, 265-279.

[11] Chapman, P. D., Oliveira, T., Livingston, A. G., \& Li, K. (2008). Membranes for the dehydration of solvents by pervaporation. Journal of Membrane Science, 318(1-2), 5-37.

[12] Shi, G. M., Zuo, J., Tang, S. H., Wei, S., \& Chung, T. S. (2015). Layer-by-layer (LbL) polyelectrolyte membrane with Nexar ${ }^{\mathrm{TM}}$ polymer as a polyanion for pervaporation dehydration of ethanol. Separation and Purification Technology, 140, 13-22.

[13] Meireles, I. T., Portugal, C., Alves, V. D., Crespo, J. G., \& Coelhoso, I. M. (2015). Impact of biopolymer purification on the structural characteristics and transport performance of composite polysaccharide membranes for pervaporation. Journal of Membrane Science, 493, 179-187. 
[14] Toti, U. S., \& Aminabhavi, T. M. (2004). Synthesis and characterization of polyacrylamidegrafted sodium alginate membranes for pervaporation separation of water + isopropanol mixtures. Journal of Applied Polymer Science, 92(3), 2030-2037.

[15] Toti, U. S., \& Aminabhavi, T. M. (2004). Different viscosity grade sodium alginate and modified sodium alginate membranes in pervaporation separation of water + acetic acid and water + isopropanol mixtures. Journal of Membrane Science, 228(2), 199-208.

[16] Naidu, B.K., Sairam, M., Raju, K., \& Aminabhavi, T. (2005). Thermal, viscoelastic, solution and membrane properties of sodium alginate/hydroxyethylcellulose blends. Carbohydrate Polymers, 61(1), 52 60.

[17] Naidu, B.V.K., Rao, K.S.V.K., \& Aminabhavi, T.M. (2005). Pervaporation separation of water+1,4dioxane and water+tetrahydrofuran mixtures using sodium alginate and its blend membranes with hydroxyethylcellulose - A comparative study. Journal of Membrane Science, 260(1-2), 131-141.

[18] Ozdemir, S., Buonomenna, M., \& Drioli, E. (2006). Catalytic polymeric membranes: preparation and application. Applied Catalysis A: General, 307(2), 167-183.

[19] Bruggen, B.V. (2010). Pervaporation Membrane Reactors. Comprehensive Membrane Science and Engineering $1^{\text {st }}$ ed. Academic Press, Oxford, 135-163.

[20] Peters, T.A. (2006). Catalytic pervaporation membranes for close integration of reaction and separation, Phd Thesis, Technische Universiteit Eindhoven, Eindhoven.

[21] Zhu, M.-H., Feng, Z.-J., Hua, X.-M., Hu, H., Xia, S.-L., Hu, N., Kita, H. (2016). Application of a mordenite membrane to the esterification of acetic acid and alcohol using sulfuric acid catalyst. Microporous and Mesoporous Materials, 233, 171-176.

[22] Sert, E., \& Atalay, F. S. (2014). n-Butyl acrylate production by esterification of acrylic acid with n-butanol combined with pervaporation. Chemical Engineering and Processing: Process Intensification, 81, 41-47.

[23] Parulekar, S. J. (2007). Analysis of pervaporation-aided esterification of organic acids. Industrial \& Engineering Chemistry Research, 46(25), 8490-8504.

[24] Peters, T. A., Benes, N. E., \& Keurentjes, J. T. F. (2005). Zeolite-coated ceramic pervaporation membranes; pervaporation-esterification coupling and reactor evaluation. Industrial \& Engineering Chemistry Research, 44(25), 9490-9496.

[25] Figueiredo, K. C. de S., Salim, V. M. M., \& Borges, C. P. (2008). Synthesis and characterization of a catalytic membrane for pervaporation-assisted esterification reactors. Catalysis Today, 133-135, 809-814.

[26] Dioos, B. M. L., Vankelecom, I. F. J., \& Jacobs, P. A. (2006). Aspects of immobilisation of catalysts on polymeric supports. Advanced Synthesis \& Catalysis, 348(12-13), 1413-1446.

[27] Shaban, H. I. (1998). Hydrolysis of ethyl acetate:a pervaporation study. European Polymer Journal, 34(7), 955-973.

[28] Nandiwale, K. Y., Sonar, S. K., Niphadkar, P. S., Joshi, P. N., Deshpande, S. S., Patil, V. S., \& Bokade, V. V. (2013). Catalytic upgrading of renewable levulinic acid to ethyl levulinate biodiesel using dodecatungstophosphoric acid supported on desilicated H-ZSM-5 as catalyst. Applied Catalysis A: General, 460-461, 90-98. 
[29] Fernandes, D. R., Rocha, A. S., Mai, E. F., Mota, C. J. A., \& Teixeira da Silva, V. (2012). Levulinic acid esterification with ethanol to ethyl levulinate production over solid acid catalysts. Applied Catalysis A: General, 425-426, 199-204.

[30] Kuwahara, Y., Fujitani, T., \& Yamashita, H. (2014). Esterification of levulinic acid with ethanol over sulfated mesoporous zirconosilicates: Influences of the preparation conditions on the structural properties and catalytic performances. Catalysis Today, 237, 18-28.

[31] Omota, F., Dimian, A. ., \& Bliek, A. (2003). Fatty acid esterification by reactive distillation: Part 2kinetics-based design for sulphated zirconia catalysts. Chemical Engineering Science, 58(14), 3175-3185.

[32] Zatta, L., Gardolinski, J. E. F. da C., \& Wypych, F. (2011). Raw halloysite as reusable heterogeneous catalyst for esterification of lauric acid. Applied Clay Science, 51(1-2), 165-169.

[33] Unlu, D., \& Durmaz Hilmioglu, N. (2016). Synthesis of Ethyl Levulinate as a Fuel Bioadditive by a Novel Catalytically Active Pervaporation Membrane. Energy \& Fuels, 30(4), 2997-3003.

[34] Rezac, M.E. (2000). Catalytic Membrane Reactors. Encyclopedia of Separation Science $1^{\text {st }}$ ed. Academic Press, Germany,1676-1682.

[35] Chopade, S.P., Mahajani, S.M. (2000). Pervaporation:Membrane Separations. Encyclopedia of Separation Science, $1^{\text {st }}$ ed. Academic Press, Germany, 3636-3638.

[36] Zhu, Y., Xia, S., Liu, G., \& Jin, W. (2010). Preparation of ceramic-supported poly(vinyl alcohol)-chitosan composite membranes and their applications in pervaporation dehydration of organic/water mixtures. Journal of Membrane Science, 349(1-2), 341-348.

[37] Feng, X., \& Huang, R. Y. M. (1997). Liquid separation by membrane pervaporation: a review. Industrial \& Engineering Chemistry Research, 36(4), 1048-1066.

[38] Solak, E.K. (2005). Separation of dimethylformamide-water mixtures using sodium alginate, sodium alginate/poly(vinyl pyrrolidone) and N-vinyl-2-pyrrolidone-g-sodium alginate membranes, Phd Thesis, Gazi University, Institute of Science and Technology, Ankara.

[39] Brüschke, H.E.A., Wynn, N.P. (2000). Membrane Separations/Pervaporation. Encyclopedia of Separation Science, Academic Press, Germany, 1776-1778.

[40] Doğan, H. (2007). Zeolite filled polimeric membranes for pervaporation applications, Phd Thesis, Kocaeli University, Institute of Science and Technology, Kocaeli.

[41] Ceia, T. F., Silva, A. G., Ribeiro, C. S., Pinto, J. V., Casimiro, M. H., Ramos, A. M., \& Vital, J. (2014). PVA composite catalytic membranes for hyacinth flavour synthesis in a pervaporation membrane reactor. Catalysis Today, 236, 98-107.

[42] Unlu, D., \& Hilmioglu, N. D. (2016). Pervaporation catalytic membrane reactor study for the production of ethyl acetate using $\mathrm{Zr}\left(\mathrm{SO}_{4}\right)_{2} \cdot 4 \mathrm{H}_{2} \mathrm{O}$ coated chitosan membrane. Journal of Chemical Technology \& Biotechnology, 91(1), 122-130.

[43] Xu, W., Xu, J., Gao, L., \& Xiao, G. (2015). Preparation and characterization of inorganic acid catalytic membrane for biodiesel production from oleic acid. Asia-Pacific Journal of Chemical Engineering, 10(6), 851-857.

[44] Assabumrungrat, S., Phongpatthanapanich, J., Praserthdam, P., Tagawa, T., \& Goto, S. (2003). Theoretical study on the synthesis of methyl acetate from methanol and acetic acid in pervaporation membrane reactors: effect of continuous-flow modes. Chemical Engineering Journal, 95(1-3), 57-65. 
[45] Buonomenna, M. G., Choi, S. H., \& Drioli, E. (2010). Catalysis in polymeric membrane reactors: the membrane role. Asia-Pacific Journal of Chemical Engineering, 5(1), $26-34$.

[46] Zhang, F. (2012). Development and scale-up of enhanced polymeric membrane reactor systems for organic synthesis. Ph.D. Thesis, Kansas State University, Manhattan.

[47] Li, J., Chen, X., Qi, B., Luo, J., Zhuang, X., Su, Y., \& Wan, Y. (2013). Continuous acetone-butanolethanol (abe) fermentation with in situ solvent recovery by silicalite-1 filled pdms/pan composite membrane. Energy \& Fuels, 28(1), 555-562.

[48] Nunes, S.P. \& Peinemann, K.V. (2006). Membrane Technology in the Chemical Industry, Wiley, Germany, $354 \mathrm{pp}$.

[49] Sun, H., Sun, D., Shi, X., Li, B., Yue, D., Xiao, R., Ren, P., Zhang, J. (2020). PVA/SO ${ }_{4}^{2-}-\mathrm{AAO}$ difunctional catalytic-pervaporation membranes: Preparation and characterization. Separation and Purification Technology, 241, 116739.

[50] Li, M., Zhang, W., Zhou, S., \& Zhao, Y. (2020). Preparation of poly (vinyl alcohol)/palygorskite-poly (ionic liquids) hybrid catalytic membranes to facilitate esterification. Separation and Purification Technology, 230, 115746.

[51] Cao, Z., Xia, C., Jia, W., Qing, W., \& Zhang, W. (2020). Enhancing bioethanol productivity by a yeastimmobilized catalytically active membrane in a fermentation-pervaporation coupling process. Journal of Membrane Science, 595, 117485.

[52] Li, Y., Han, S., Zhang, L., Li, W., \& Xing, W. (2019). Fabrication and modeling of catalytic membrane for removing water in esterification. Journal of Membrane Science, 579, 120-130.

[53] Zhang, L., Li, Y., Liu, Q., Li, W., \& Xing, W. (2019). Fabrication of ionic liquids-functionalized PVA catalytic composite membranes to enhance esterification by pervaporation. Journal of Membrane Science. $584,268-281$.

[54] Unlu, D., \& Durmaz Hilmioglu, N. (2019). Production Of Fuel Bioadditive "Triacetin" by using phosphomolybdic acid loaded pva membrane in pervaporation catalytic membrane reactor. Energy \& Fuels, 33, 2208-2218.

[55] Unlu, D., \& Hilmioglu, N. D. (2018). Pervaporation catalytic membrane reactor application over functional chitosan membrane. Journal of Membrane Science, 559, 138-147.

[56] Unlu, D., Ilgen, O., \& Durmaz Hilmioglu, N. (2017). Reactive separation system for effective upgrade of levulinic acid into ethyl levulinate. Chemical Engineering Research and Design, 118, 248-258.

[57] Nigiz, F. U., \& Hilmioglu, N. D. (2016). Simultaneous separation performance of a catalytic membrane reactor for ethyl lactate production by using boric acid coated carboxymethyl cellulose membrane. Reaction Kinetics, Mechanisms and Catalysis, 118(2), 557-575.

[58] Nigiz, F. U., \& Hilmioglu, N. D. (2016). Rhizomucor miehei lipase-immobilized sodium alginate membrane preparation and usage in a pervaporation biocatalytic membrane reactor. Chemical and Biochemical Engineering Quarterly, 30, 381-391.

[59] Qing, W., Wu, J., Chen, N., Liu, L., Deng, Y., \& Zhang, W. (2017). A genuine in-situ water removal at a molecular lever by an enhanced esterification-pervaporation coupling in a catalytically active membrane reactor. Chemical Engineering Journal, 323, 434-443. 
[60] Zhang, W., Qing, W., Chen, N., Ren, Z., Chen, J., \& Sun, W. (2014). Enhancement of esterification conversion using novel composite catalytically active pervaporation membranes. Journal of Membrane Science, 451, 285-292.

[61] Zhang, W., Qing, W., Ren, Z., Li, W., \& Chen, J. (2014). Lipase immobilized catalytically active membrane for synthesis of lauryl stearate in a pervaporation membrane reactor. Bioresource Technology, $172,16-21$.

[62] Liu, Q. (2002). Modeling of esterification of acetic acid with n-butanol in the presence of $\mathrm{Zr}(\mathrm{SO} 4) 2 \cdot 4 \mathrm{H} 2 \mathrm{O}$ coupled pervaporation. Journal of Membrane Science, 196(2), 171-178.

[63] Yushan Zhu, \& Hongfang Chen. (1998). Pervaporation separation and pervaporation-esterification coupling using crosslinked PVA composite catalytic membranes on porous ceramic plate. Journal of Membrane Science, 138(1), 123-134.

[64] Ma, X.-H., Wen, X., Gu, S.-W., Xu, Z.-L., \& Zhang, J.-L. (2013). Preparation and characterization of catalytic $\mathrm{TiO}_{2}-$ SPPESK-PES nanocomposite membranes and kinetics analysis in esterification. Journal of Membrane Science, 430, 62-69.

[65] Peters, T. A., Benes, N. E., \& Keurentjes, J. T. F. (2007). Preparation of Amberlyst-coated pervaporation membranes and their application in the esterification of acetic acid and butanol. Applied Catalysis A: General, 317(1), 113-119.

[66] Peters, T. A., van der Tuin, J., Houssin, C., Vorstman, M. A. G., Benes, N. E., Vroon, Z. A. E. P., ... Keurentjes, J. T. F. (2005). Preparation of zeolite-coated pervaporation membranes for the integration of reaction and separation. Catalysis Today, 104(2-4), 288-295.

[67] Liu, Q., Jia, P., \& Chen, H. (1999). Study on catalytic membranes of H3PW12O40 entrapped in PVA. Journal of Membrane Science, 159(1-2), 233-241.

[68] Figueiredo, K. C. de S., Salim, V. M. M., \& Borges, C. P. (2008). Synthesis and characterization of a catalytic membrane for pervaporation-assisted esterification reactors. Catalysis Today, 133-135, 809-814.

[69] Bagnell, L., Cavell, K., Hodges, A. M., Mau, A. W.-H., \& Seen, A. J. 1993. The use of catalytically active pervaporation membranes in esterification reactions to simultaneously increase product yield, membrane permselectivity and flux. Journal of Membrane Science, 85(3), 291-299.

[70] David, M. O., Nguyen, Q. T., \& Néel, J. (1992). Pervaporation membranes endowed with catalytic properties, based on polymer blends. Journal of Membrane Science, 73(2-3), 129-141. 